\title{
THE PARAMETER CORRELATION OF ACOUSTIC EMISSION AND HIGH-FREQUENCY VIBRATIONS IN THE ASSESSMENT PROCESS OF THE OPERATING STATE OF THE TECHNICAL SYSTEM
}

\author{
Petr BARON*, Jozef DOBRÁNSKY*, Martin POLLÁK*, Marek KOČIŠKO*, Tomáš CMOREJ* \\ ${ }^{*}$ Faculty of Manufacturing Technologies, Department of Computer Aided Manufacturing Technologies, \\ Technical University of Košice, Štúrova 31, 08001 Prešov, Slovakia \\ petr.baron@tuke.sk, jozef.dobransky@tuke.sk, martin.pollak@tuke.sk, marek.kocisko@tuke.sk, tomas.cmorej@tuke.sk
}

received 23 October 2015, revised 10 May 2016, accepted 13 May 2016

\begin{abstract}
The article describes application of selected methods of technical diagnostics for assessing the operating status of precision gearboxes. Within the confines of experimental measurements in the field of physical metallurgy materials of diagnosed system were being examined while taking into account the process of degradation of material properties during operation of monitored gearboxes. Measurements and collecting of dynamic data were realized on 4 selected gearboxes where a high-frequency vibrations and acoustic emission (noise) measurements were carried out. Retrieved values were subsequently used for mutual correlation and verification of applied methods. Results of both selected methods underlined unsatisfactory operation status with 3 inspected gearboxes. Measured values were identified as being above suggested caution limit of Alarm 2, representing a level of danger.
\end{abstract}

Key words: Technical Diagnostics, Vibrodiagnostics, Analysis of Dynamic Signal

\section{INTRODUCTION}

The most important role of technical diagnostics lies in predicting the technical condition of the system being assessed. One of the objectives of technical diagnostics is predicting of duration of flawless operation, i.e. time interval between observed moment up to occurrence of failure. The failure prediction is based on identification of deterioration in the condition of assessed systems and determining the moment when it is necessary to implement appropriate measures in order to prevent failures and undesired damage (Janoušek et al, 1988; Valent et al., 2010; Panda and Prislupčák, 2014).

Basic tasks of diagnostics is to determine the diagnosis characterizing the technical state of the object in terms of failures and this diagnosis must be usable for optimizing the servicing (maintenance) actions in order to bring the object to normal state. Monitored features of diagnosed object are vital for the success of the diagnostic system. One of the most important properties is diagnosability, i. e, feature that allows you to obtain information about the technical condition using diagnostic tools; in other words it presents the capacity of the object for the use of diagnostic equipment. The machine is sufficiently diagnosable if it is possible to perform all diagnostic tasks easily with required accuracy and, if possible, low cost (Valent et al., 2010; Hreha et al., 2010; Michalik et al., 2014; Šebo et al., 2013).

In the process of technical diagnosis variety of techniques is applied to diagnose machines but it often happens that the measurements are not interpreted or interpretation is not correct. Within the frame of vibration diagnostics there are occurrences of realizing the very collecting and recording of the vibrations signals while ignoring the force and energy that causes fatigue damage to machine parts and thusly shortens their lifespan.
It means that twice the force shortens durability of the bearings to $1 / 8$ of technical serviceability and device's lifespan is reduced from $5-10$ years to only several months. Bearing diagnostics is a very demanding field and if technical diagnostician relies only on "their" method, the results of their work can even be fatal. Bearing damage can be caused by unsuiTab. lubricant, contaminated lubricant, water, excessive force, oxidation and degradation of the lubricant additives. The human factor can cause that bearing is installed with a larger overlap, overheated during installation or it is over-lubricated, insufficiently lubricated or without oil. These difficulties can shorten the bearing lifespan by a few hours up to several months (Valent et al., 2010; Šebo et al., 2013; Stejskal et al., 2013; Šoltésová and Baron, 2013; Jurko et al., 2011).

Based on cooperation of our department with practice the demand arose for accurate assessment of the operating condition of gearboxes. Four selected gearboxes were analyzed. In the context of diagnostic it was applied measurement of highfrequency vibration and acoustic emission. The measured values were used for the cross-correlation and verification of selected methods.

\section{DESCRIPTION OF THE MEASURING - CHARACTERISTICS OF THE MACHINES AND MEASURING METHODS}

In the process of diagnostic activities for the purpose of vibration measurement, process data collection and subsequent analysis the following diagnostics systems were used:

- the frequency analyzer and Data Collector Microlog GX,

- the software interface of Aptitude Analyst,

- vibration sensor, accelerometer Wilcoxon Research Model 
SKF786M, sensitivity $100 \mathrm{mV} / \mathrm{g}$, frequency range from 1 to $20000 \mathrm{~Hz}$.

Used measuring method based on recommendations of the technical standard STN ISO 10816-3 - Mechanical oscillation. Evaluation of machine oscillation by measuring on non-rotating parts of machine.

For purpose of vibration assessment in the low frequency area the following were applied:

- The measurement method Velocity (vibration velocity), unit $\mathrm{mm} / \mathrm{s}$, RMS detection.

- According to the recommendations of ISO 10816-3, FFT (Fast Fourier Transform) frequency spectrum for the area from 10 to $800 \mathrm{~Hz}$.

- The measurement method Enveloping Acceleration (method of measuring the vibration acceleration in the high frequency range to $10-20 \mathrm{kHz}$ through which assessment is carried out in particular for the state of the rolling bearings and gear ratio), unit $\mathrm{Eg}$, detection of PtP, the frequency area from 50 to $1000 \mathrm{~Hz}$, FFT spectrum and time record.

For the assessment of vibration in the high-frequency area the following methods were used:

- The measurement method Acceleration (vibration acceleration), unit $\mathrm{g}$, detection of PtP, frequency range up to $16 \mathrm{kHz}$, the FFT spectrum and time record.
- The measurement method Acceleration Enveloping, unit Eg, detection of PTP, Frequency range up to $10 \mathrm{kHz}$ to $20 \mathrm{kHz}$, the FFT spectrum and time.

Diagnostic methods for the assessment of acoustic emission and ultrasound:

- The measurement method See (Spectral Emitted Energy) acoustic emissions (SKF), a unit See, detection of PtP, frequency range up to $600 \mathrm{kHz}$, the FFT spectrum and time record.

- The measurement method HFD - High Frequency detection method (SKF), analysis of vibration (acceleration) in frequencies $40 \mathrm{kHz}$.

- Method for assessment of the state of lubrication, resistance of the oil film, metallic contact, sticking, abrasion of contact surfaces (bearings and gear).

\section{RECORDING AND RUNNING OF OPERATING PARAMETERS - REALIZATION OF THE EXPERIMENTAL MEASUREMENTS}

Tab. 1 contains a summary of the measured values of the exposure of noise and vibrations of the individual gearboxes marked $A, B, C, D$.

Tab. 1. Measured exposure values for noise and vibrations of gearboxes $A, B, C, D$

\begin{tabular}{|c|c|c|c|c|c|c|c|}
\hline \multirow{4}{*}{ Gearbox } & \multicolumn{3}{|c|}{ HF vibrations - oscillations } & \multicolumn{3}{|c|}{ Sound - noise } & \multirow{3}{*}{ Evaluation } \\
\hline & Acc & Acc & EnvAcc & LAeq & LASmax & LAlmax & \\
\hline & [g] & [g] & [gE] & [dB] & {$[\mathrm{dB}]$} & [dB] & \\
\hline & To $20 \mathrm{kHz}$ & $\begin{array}{c}\text { Zone } 1 \text { - } 6 \\
\text { kHz }\end{array}$ & To $10 \mathrm{kHz}$ & & & & \\
\hline A & 8.09 & 6.87 & 3.67 & 79.5 & 81.0 & 84.6 & A2 \\
\hline B & 5.30 & 4.49 & 2.45 & 73.6 & 74.7 & 78.0 & A2 \\
\hline C & 4.43 & 3.07 & 1.58 & 72.5 & 73.8 & 75.5 & A2 \\
\hline $\mathrm{D}$ & 3.20 & 1.37 & 0.92 & 72.4 & 73.5 & 74.6 & SUITAB. \\
\hline ALARM 1 (A1) & 3.30 & 2.20 & 1.00 & - & - & - & \\
\hline ALARM 2 (A2) & 4.30 & 3.00 & 1.50 & 75.0 & 75.0 & 75.0 & \\
\hline
\end{tabular}

Explanatory notes: Acc - acceleration of vibration displacement, EnvAcc - envelope of vibration acceleration, Laeq - value of the equivalent level of acoustic pressure A, LASmax - the maximum level of acoustic pressure using the weighting filter type A and the time constant "Slow", LAlmax - the maximum level of acoustic pressure using the weighting filter type A and the time constant "Impulse".

The measured acceleration values were obtained by diagnostic system with the application of accelerometer Wilcoxon Research, SKF786M in cooperation with the PorTab. Data Collector/FFT Analyzer SKF Microlog Analyzer (Fig. 3). The gearboxes were measured at one measuring point (acceleration).

The values of alarm levels (primarily for noise limits, sound pressure, acoustic emission and high frequency acceleration) are determined by the following ways:

- by agreement between a supplier (manufacturer) and customers,

- when the signal increase over $200 \%$ compared to the reference (agreed) level measured on the normal product quality and design,

- by comparing the dynamic characteristics of competing manufacturers - suppliers), respectively by comparing the measured values with the normal level of the same products in the local market.

In the specific case of defined alarm set points were based on an analysis of signal levels of $95 \%$ of the measured values of controlled amount of the same types of mechanisms (see. Tab. 1).

From the diagram of the measured values of the gearbox "A" (Fig. 4) it is seen that the value of the frequency about $2700 \mathrm{~Hz}$ achieved the level of noise $81 \mathrm{~dB}$, respectively $84,6 \mathrm{~dB}$.

FFT spectrum of a vibration signal confirmed the statement as with value about $2700 \mathrm{~Hz}$ measured signal value was: EnvAcc - $3.67(\mathrm{gE})$, Acc $-6.87(\mathrm{~g})$, Acc - $8.09(\mathrm{~g})$. Time record of signal points to the unsatisfactory operating condition of the gearbox (Fig. 5). In both cases the measured values are set above the limit of alarm A2 (see Tab. 1). 


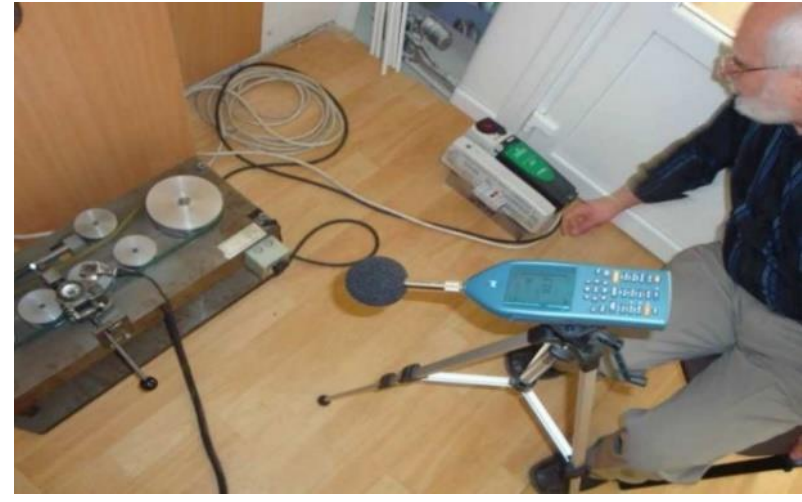

Fig. 1. The sound pressure measurement

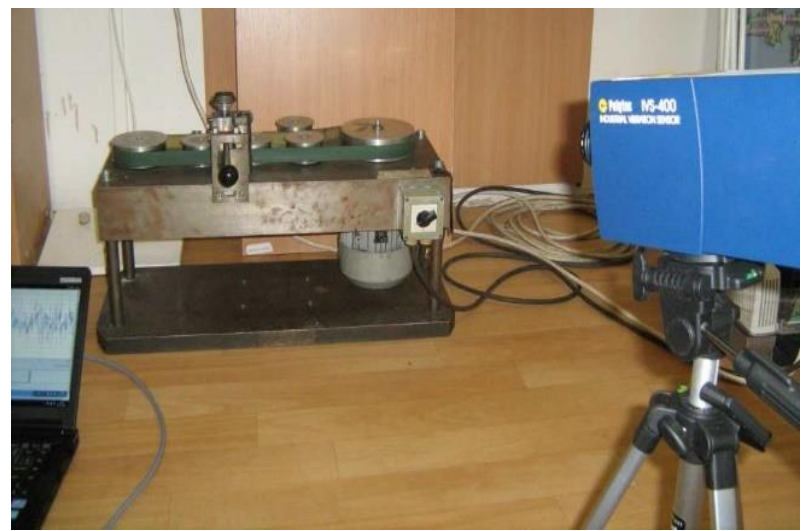

Fig. 2. The contactless measuring of vibration by the laser vibrometer
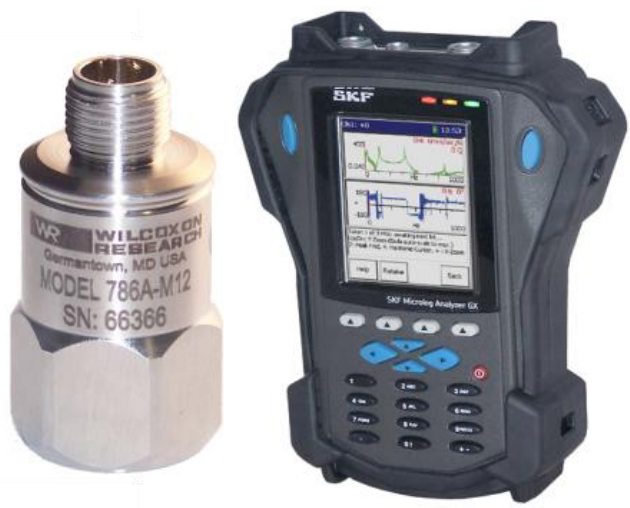

Fig. 3. Accelerometer model Wilcoxon Research, SKF786M and PorTab. Data Collector/FFT Analyzer SKF Microlog Analyzer

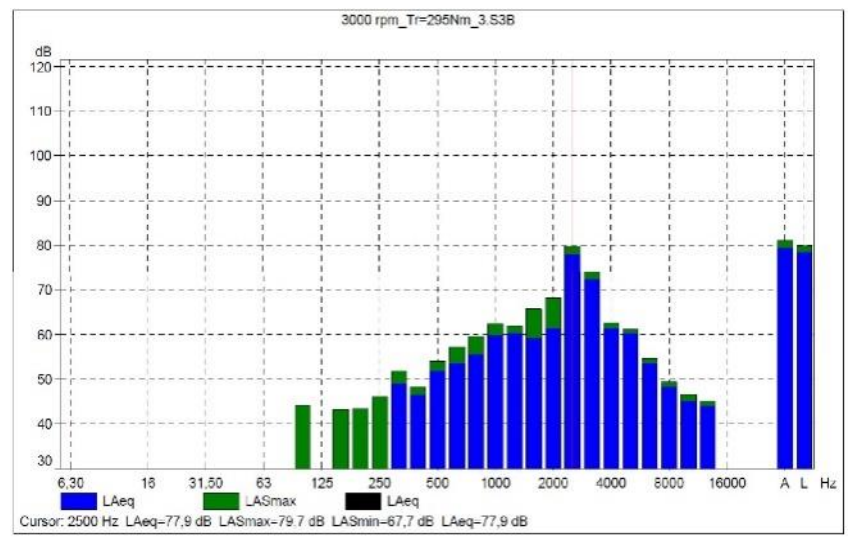

Fig. 4. Graphic record of acoustic emission for gearbox "A"
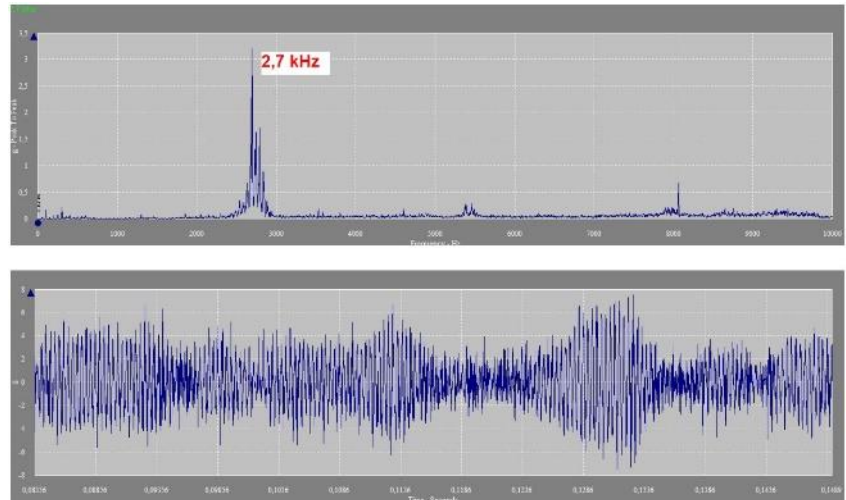

Fig. 5. FFT spectrum and recording TIME of gearbox „A“

In the case of the gearbox marked by the symbol "B" it is possible to record the state from the diagram when the vibration value about $4000 \mathrm{~Hz}$ is equal to the noise level of $74,7 \mathrm{~dB}$ and $78 \mathrm{~dB}$ (Fig. 6).

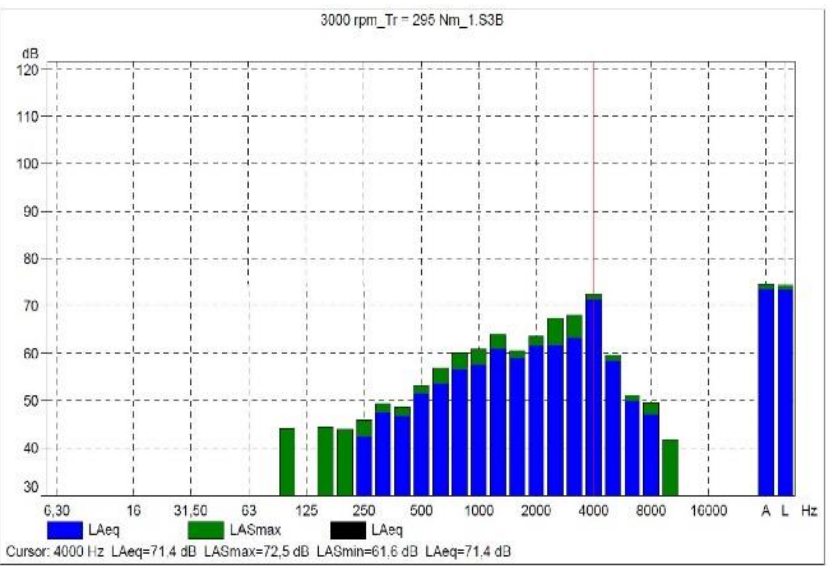

Fig. 6. The graphic record of acoustic emission for gearbox "B"

FFT spectrum of a vibration signal confirms the state where with value about $4200 \mathrm{~Hz}$ the measured signal value was: EnvAcc - $2.45(\mathrm{gE})$, Acc $-4.49(\mathrm{~g})$, Acc $-5.30(\mathrm{~g})$. Time record of signal points to the unsatisfactory operating condition of the gearbox " $B$ " (Fig. 7). In both cases the measured values are set above the limit of alarm $\mathrm{A} 2$.
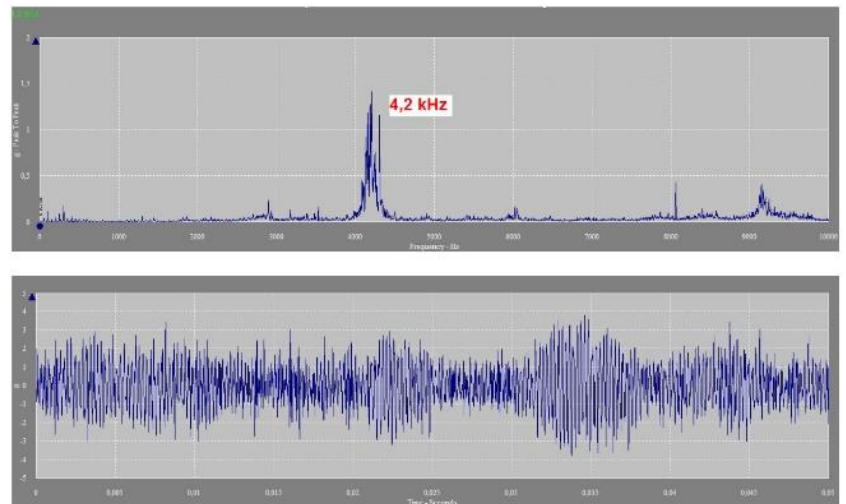

Fig. 7. FFT spectrum and recording TIME of gearbox „B“ 
For the third case - gearbox " $\mathrm{C}$ " in the vibration value about $4000 \mathrm{~Hz}$ had a vibration sound emission moving at the level of 73.8 and $75.5 \mathrm{~dB}$ (Fig. 8). FFT spectrum of a vibration signal confirmed that with value around $4150 \mathrm{~Hz}$ the measured signals value was: EnvAcc - 1.58 (gE), Acc - 3.07 (g), Acc - $4.43(\mathrm{~g})$. Time record of signal points to the unsatisfactory operating condition of the gearbox "C" (Fig. 9). In both cases the measured values are set above the limit of alarm A2.

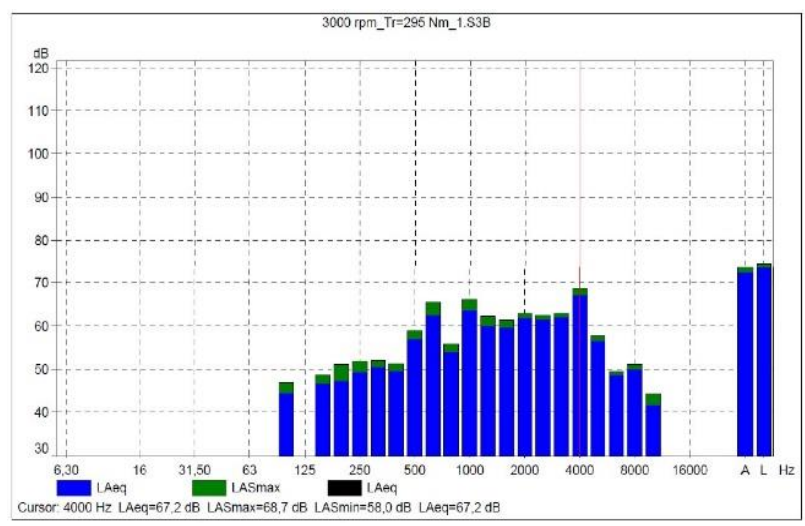

Fig. 8. The graphic record of acoustic emission for gearbox "C"
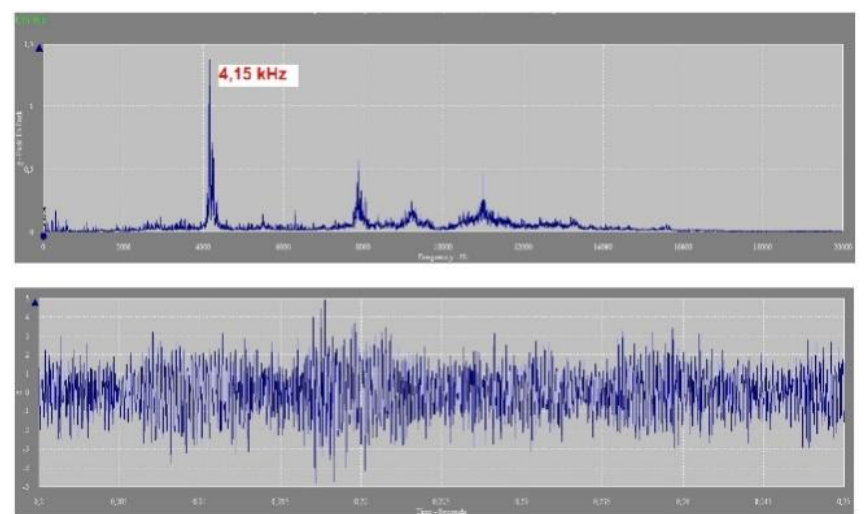

Fig. 9. FFT spectrum and recording TIME of gearbox "C"

In the case of the last gearbox marked by the symbol "D" was recorded a state where the all zones were located below level of $70 \mathrm{~dB}$ without dominant frequencies across the whole monitored zone.

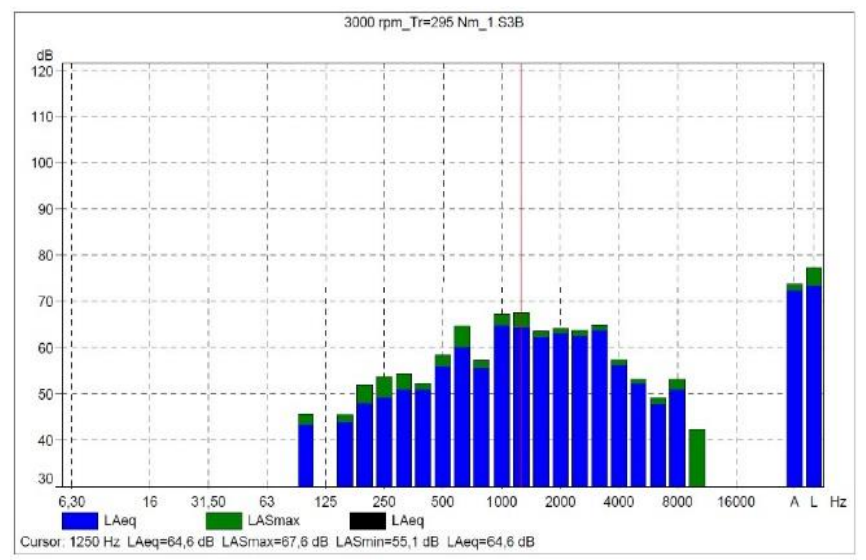

Fig. 10. Graphic record of acoustic emission for gearbox "D"
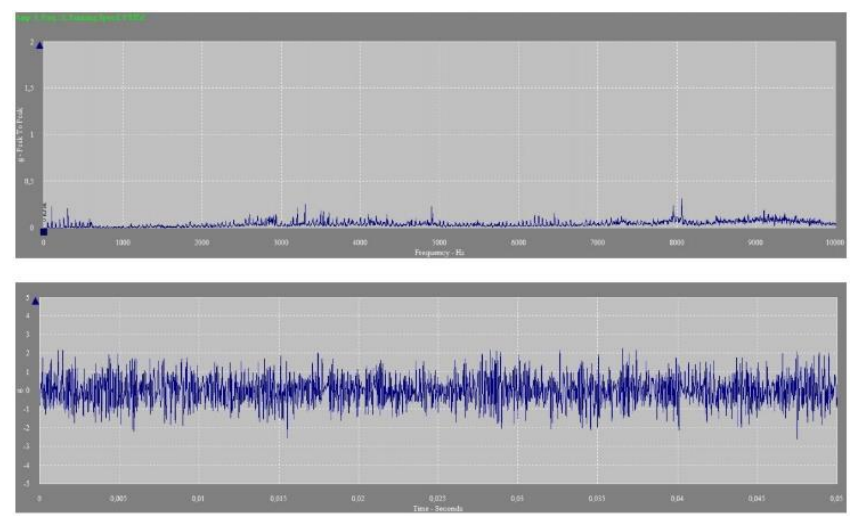

Fig. 11. FFT spectrum and recording TIME of gearbox „D“

FFT spectrum of the vibration signal also confirms that within measurement area there is not a state of increased signal. The measured signal value was: EnvAcc - 0,92 (gE), Acc - 1,37 (g), Acc $-3,20(\mathrm{~g})$. Time record points to the satisfactory operating condition of the gearbox (Fig. 11). The measured values of both cases are within the defined limits, i.e. condition is satisfactory.

\section{CONCLUSION}

Noise and vibrations are closely related since in many cases the oscillating bodies are the cause of secondarily created noise and vice versa - air-transmitted acoustic energy can create interfering oscillation of constructions, worsening of workplace conditions etc. (Jurko et al., 2010; Dobránsky et al., 2015; Balthazar et al., 2013). The causes of vibration in technical practice are alternate forces that arise from the clearance and inaccuracies in rotating movements of machines, in vehicles movement and their parts, at work with the various machine tools, etc. Primary task of vibration diagnostics is early identification of moment of required maintenance or possibly changing the segment in assessed system before end of its working life. This type of diagnostics increases security, reliability and durability, the period between two repairs respectively. Finally, thereby reducing maintenance costs (Warminski et al., 2013; Hyung-Deok and Hun Lee, 2014; Wereley and Meinhart, 2010; Gallagher et al., 2012).

In respect to case of diagnostics of assessed precision gearboxes described in the article it is possible, based on realized measurements and analysis of dynamic signal by means of correlation of two methods, to state the following conclusion:

- operating state of gearboxes "A", "B" and "C" is unsatisfactory. The measured values are identified above the recommended limit of warning Alarm 2 (A2 - danger),

- gearbox "D" is in satisfactory working condition for all measured parameters and measurement methods.

After the realized repair of gearboxes "A" to " $\mathrm{C}$ " it is recommended to re-diagnose their operating status by measuring highfrequency vibrations. Consequently it is desirable, by measuring the microgeometry of contact surfaces, to assign the measured value of high dynamic signal for specific gearbox component, and define its eventual production inaccuracy (Asiri, 2007). 


\section{REFERENCES}

1. Asiri S. (2007) Tunable mechanical filter for longitudinal vibrations, Shock and Vibration, 14(5), 377-391.

2. Balthazar J. M., Gonçalves P.B., Fenili A. (2013) Nonlinear vibrations in elastic structures:Dynamics and control, Shock and Vibration, 20(6), 1031-1032

3. Dobránsky J., Baron P., Simkulet V., Kočiško M., Ružbarský J., Vojnová E. (2015) Examination of material manufactured by direct metal laser sintering (DMLS), Metalurgija, 54(3), 477-480.

4. Gallagher K. S., Grübler A., Kuhl L., Nemet G., Wilson Ch. (2012) The Energy Technology Innovation System, Annual Review of Environment and Resource, 37, 137-162.

5. Hreha P., Hloch S., Valíček J., Monková K., Monka P., Harničárová M., Fusek M., Konjatić P. (2010), Impact of abrasive mass flow rate when penetrating into a material on its vibration, Tehnički vjesnik - Technical Gazette, 17(4), 475-479.

6. Hyung-Deok S., Hun L. (2014) Disentangling the role of knowledge similarity on the choice of alliance structure, Journal of Engineering and Technology Management, 30(4), 350-362.

7. Janoušek I., Kozák J., Taraba J. (1988), Technical Diagnostics. SNTL Praha.

8. Jurko J., Džupon M., Panda A., Gajdoš M., Pandová I. (2011), The deformation under the machined surface material in the production of drilling holes into the austenitic stainless steel, Chemické listy, 105(16), 600-602.

9. Jurko J., Gajdoš M., Panda A. (2010) Study of changes under the machined surface and accompanying phenomena in the cutting zone during drilling of stainless steels with low carbon content, Metalurgija, 50(2), 113-117.

10. Michalik P., Zajac J., Hatala M., Hutyrová Z., Mital' D., Olhova J. (2014), Comparison Measurement of the Distance between Axes of Holes with the Roundtest RA-120 and Thome Präzision-Rapid, Applied Mechanics and Materials, 616, 284-291.

11. Panda A., Prislupčák M. (2014), Analysis of technological factors, Studia i materialy, 34(1), 13-16.

12. Šebo J., Buša J., Demeč P., Svetlík J. (2013), Optimal replacement time estimation for machines and equipment based on cost function, Metalurgija, 52(1), 119-122.
13. Šoltésová S., Baron P. (2013), The Operation Monitoring Condition of the Production Machinery and Facilities Using the Tools of Technical Diagnostics, Applied Mechanics and Materials, 308, 105-109.

14. Stejskal T., Kováč J., Valenčík Š. (2013), Mechanism of randomness in vibration signals of machinery, Applied Mechanics and Materials, 282, 257-262.

15. Valent O., Galád M., Kačmár L'. (2010), Technical Diagnostics, 1, Condition Monitoring and Maintenance Systems, CMMS, Prague

16. Warminski J., Cartmell M.P., Mitura A., Bochenski M., (2013) Active vibration control of a nonlinear beam with self- and external excitations, Shock and Vibration, 20 (6), 1033-1047.

17. Wereley S. T., Meinhart C. D., (2010) Recent Advances in MicroParticle Image Velocimetry, Annual Review of Fluid Mechanics, 42, 557-576.

Acknowledgements: Ministry of Education, Science, Research and Sport of SR supported this work, contract VEGA No. 1/0032/12 and ITMS project 26220220125 .

We support research activities in Slovakia/
Project is cofinanced from fonds of EU.

